Journal of Economic, Business and Accounting (COSTING)

Volume 2 Nomor 1, Juli-Desember 2018

e-ISSN : 2597-5234

https://doi.org/10.31539/costing.v2i1.426

\title{
PENGARUH KUALITAS SISTEM INFORMASI AKADEMIK TERHADAP KEPUASAN DAN LOYALITAS MAHASISWA PERGURUAN TINGGI
}

\section{THE EFFECT OF ACADEMIC INFORMATION SYSTEM QUALITY ON COLLEGE STUDENT SATISFACTION AND LOYALTY}

\author{
Astri Ayu Purwati ${ }^{1}$, Muhammad Luthfi Hamzah², Hamzah³ ${ }^{3}$, Sarli Rahman ${ }^{4}$ \\ Sekolah Tinggi Ilmu Ekonomi Pelita Indonesia ${ }^{1,4}$ \\ Sekolah Tinggi Ilmu Komputer Pelita Indonesia ${ }^{2}$, Universitas Islam Riau ${ }^{3}$ \\ astriayu90@gmail.com1, hamzah@fisuir.co.id2,muhammadluthfihamzah@gmail.com3, \\ sarlirahman@gmail.com ${ }^{4}$
}

\begin{abstract}
With the increasing speed of information flow due to globalization, the role of information technology is vital and very decisive for an educational institution in increasing its ability to face competition and be able to provide satisfactory services for students. The object of this research is the users of the university's academic information system, namely all active students of TA Geap 2017-2018 with a sample of 450 people. The data analysis technique used in this study is using Structural Equation Modeling (SEM) Amos. The results of the study show that improving the quality of academic information systems will be able to increase student satisfaction but not necessarily be able to increase student loyalty directly. However, indirectly through satisfaction, the quality of the system can increase user / student loyalty. Improvement and improvement of academic information also through this research directly and indirectly can have an impact on increasing student satisfaction and loyalty. Good service quality in a college is a very important assessment in increasing student satisfaction and loyalty.
\end{abstract}

Keywords: Information Technology, Satisfaction, Loyalty

\begin{abstract}
ABSTRAK
Dengan semakin meningkatnya kecepatan arus informasi akibat globalisasi, peranan teknologi informasi menjadi vital dan sangat menentukan bagi sebuah lembaga pendidikan dalam meningkatkan kemampuannya menghadapi persaingan dan mampu memberikan pelayanan yang memuaskan bagi mahasiswa. Yang menjadi objek dalam penelitian ini adalah pengguna sistem informasi akademik perguruan tinggi yaitu seluruh mahasiswa aktif TA Geap 2017-2018 dengan jumlah sampel 450 orang. Teknik analisis data yang digunakan dalam penelitian ini adalah menggunakan Structural Equation Modelling (SEM) Amos. Hasil penelitian menunjukkan peningkatan kualitas sistem informasi akademik akan dapat meningkatkan kepuasan mahasiswa namun belum tentu dapat meningkatkan loyalitas mahasiswa secara langsung. Namun, secara tidak langsung melalui kepuasan, kualitas sistem dapat meningkatkan loyalitas pengguna/mahasiswa. Peningkatan dan perbaikan informasi akademik juga melalui penelitian ini secara langsung dan tidak langsung dapat berdampak kepada peningkatan kepuasan dan loyalitas mahasiswa. Kualitas pelayanan yang baik dalam sebuah perguruan tinggi menjadi penilaian yang sangat penting dalam meningkatkan kepuasan dan loyalitas mahasiswa.
\end{abstract}

Kata Kunci : Teknologi Informasi, Kepuasan, Loyalitas

\section{PENDAHULUAN}

Perkembangan

teknologi

informasi di dunia pada umumnya dari tahun ke tahun sangat signifikan. Pengguna teknologi informasi seakan memperoleh banyak kemudahan dengan 
adanya teknologi informasi. Dengan semakin meningkatnya kecepatan arus informasi akibat globalisasi, peranan teknologi informasi menjadi vital dan sangat menentukan bagi sebuah lembaga pendidikan dalam meningkatkan kemampuannya menghadapi persaingan dan mampu memberikan pelayanan yang memuaskan bagi mahasiswa. Lembaga pendidikan tingkat perguruan tinggi yang baik tentunya harus memiliki sistem informasi akademik yang cukup, bahkan baik, untuk mahasiswa, tenaga pengajar, dan Bagian Administrasi Akademik Perguruan Tinggi itu sendiri.

Meskipun dalam beberapa hal sistem informasi akademik bagi berguruan tinggi memiliki banyak manfaat, berdasarkan survey pendahuluan (2017) diperoleh beberapa kelemahan dalam mengaplikasikan sistem informasi akademik pada perguruan tinggi di kota Pekanbaru diantaranya sebagai berikut: (1) masih adanya beberapa perguruan tinggi swasta yang belum mengimplementasikan sistem informasi akademik secara menyeluruh, masih terdapat beberapa pelayanan akademik dilakukan secara manual dan lambat, (2) ditemukan hambatan server time out ketika akses secara serentak oleh banyak user, (3) menggunakannya harus tersambung jaringan internet yang cepat, (4) memiliki beberapa tempat yang memiliki jaringan internet / hotspot area agar para mahasiswa atau dosen dapat melihat dan mengetahui informasiinformasi seputar perkuliahan secara cepat dan real time, (5) kurangnya panduan dalam mengakses sistem informasi akademik, (6) keterbatasan jumlah dan tingkat kemampuan SDM yang menguasai teknologi informasi

Selain itu, hasil penelitian Purwati \& Sitompul (2016) ditemukan hasil bahwa sistem informasi akademik seperti pelayanan pendaftaran secara online, pengisian KRS online, pemanfaatan website akademik dan e-learning dosen menjadi salah satu unsur kualitas perguruan tinggi yang berada di kategori one dimensional yang artinya atributatribut sistem informasi akademik tersebut wajib diperhatikan karena apabila tidak dipenuhi maka akan menyebabkan ketidakpuasan pengguna. Begitupula penelitian Hamzah et al (2018) mendapati bahwa sistem inormasi akademik berperan penting dalam mendukung kualitas akademik salah satu contohnya melalui informasi akademik sarana prasarana (Hamzah, 2017)

Pengukuran sistem informasi juga perlu dilakukan untuk melihat kualitas dari penggunaan sistem tersebut. Beberapa penelitian juga menunjukkan untuk mengukur sistem informasi dilihat dari kepuasan pengguna informasi (user information satisfaction), penggunaan sistem (system usage) dan nilai informasi (information value). Beberapa peneliti menurut Jogiyanto (2007) mengusulkan untuk menggunakan kepuasan pemakai sebagai pengukur penggunaan sistem informasi. Berdasarkan latar belakang tersebut di atas maka dilakukan penelitian dengan judul Information System Success Model dalam Peningkatan Kinerja Manajemen Akademik Perguruan Tinggi di Kota Pekanbaru.

Sistem merupakan suatu kesatuan yang tersusun dari sejumlah elemen. Berdasarkan pengertian tersebut di atas dapat disimpulkan bahwa sistem merupakan himpunan dari elemen-elemen yang fungsinya saling berhubungan dan terorganisasi, menjadi suatu kesatuan yang memiliki fungsi dalam menciptakan keseimbangan dan efisiensi ke atas suatu kerja. 
Dalam pengertian mengenai sebuah sistem para ahli umumnya sepakat bahwa model atau gambar umum dari sebuah sistem mencangkup gambar tentang masukannya, prosesnya dan keluarannya. Model semacam ini dinamai sebagai model "black box" (Gambar 2.1). Keluaran akan mempengaruhi lingkungan, sehingga terjadi perubahanperubahan dalam lingkungan. Informasi tentang perubahan-perubahan lingkungan akan merupakan umpan balik (feedback), yang kemudian ditangkap lagi oleh sistem sebagai masukan baru. Demikian seterusnya. Oleh sebab itu dapat kita definisikan bahwa sistem adalah satu kesatuan komponen yang saling terhubung dengan batasan yang jelas bekerja bersama-sama untuk mencapai seperangkat tujuan.

Penelitian telah menunjukkan bahwa alat teknologi saja tidak dapat digunakan sebagai suatu penyampai informasi organisasi karena dapat bersifat sumbang (Telem, 1996). Hambatan institusional termasuk faktor-faktor seperti akses data, integritas data dan teknologi ketidakcocokan menjadi pemicunya (Petrides, 2004). Ada beberapa pengamatan umum sehubungan dengan akademik ataupun institut. Mereka digambarkan sebagai berikut: (1) setiap lembaga akademis akan melihat ke depan untuk menjaga posisi strategis mereka agar dapat bersaing memperoleh keutungan, (2) setiap lembaga menginginkan manajemen dokumentasi internal dan informasi, (3) ada peningkatan permintaan untuk strategi baru yang membantu institusi akademis memenuhi tuntutan eksternal dan internal mereka.

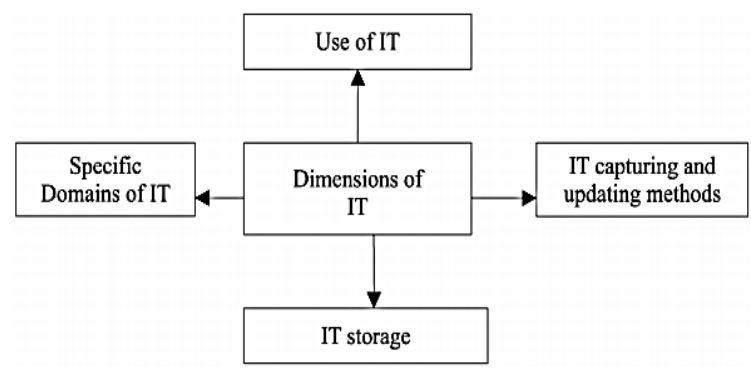

\section{Gambar 1. Dimensi IT pada Bidang Akademik}

Penerapan TI yang berhasil dalam pendidikan adalah dalam bentuk berbagi semua bentuk informasi, baik secara eksplisit maupun diam-diam. Informasi eksplisit datang dalam berbagai media seperti file komputer, e-mail, videotape, compact disk, perpustakaan digital dan buku teks. Hasil kerja individu atau kelompok proyek, direkam dan disimpan dalam semua jenis media sehingga dapat diakses dan digunakan bila diperlukan. Jenis informasi ini sangat umum tetapi masih penting dalam pembelajaran. (Scheepers dan Rose, 2001) mendiskusikan peran intranet dan peran orang yang berbagi informasi melalui intranet. Namun, informasi tacit samasama berharga. Informasi tacit leboh bersifat pribadi dan mendalam berakar pada pengalaman, nilai, dan budaya seseorang membuatnya sulit untuk menangkap, mengkodifikasikan, menyimpan, dan membagikan kepada orang lain. Walaupun jenis informasi ini tidak berwujud, tidak boleh diabaikan karena dianggap sebagai pusat inovasi dalam pembelajaran.

\section{METODE PENELITIAN Objek dan Sampel Penelitian}

Yang menjadi objek dalam penelitian ini adalah pengguna sistem informasi akademik perguruan tinggi 
yaitu mahasiswa aktif, karyawan dan manajemen pada Perguruan Tinggi kota Pekanbaru. Pemilihan sampel dilakukan dengan menggunakan metode probability sampling dengan teknik Simple Random Sampling. Jumlah Ukuran Sampel ditentukan secara proporsional berdasarkan populasi mahasiswa di perguruan tinggi Kota Pekanbaru tersebut pada tahun 2017.

Tabel 1 Daftar objek penelitian

\begin{tabular}{|c|c|c|c|}
\hline $\begin{array}{c}\text { Jenis } \\
\text { Perguruan } \\
\text { Tinggi } \\
\end{array}$ & Nama & $\begin{array}{c}\text { Jumlah } \\
\text { Mahasiswa }\end{array}$ & $\begin{array}{c}\text { Jumlah } \\
\text { Responden }\end{array}$ \\
\hline \multirow[t]{2}{*}{ Universitas } & $\begin{array}{l}\text { Universitas Lancang } \\
\text { Kuning }\end{array}$ & 7733 & 104 \\
\hline & Universitas Islam Riau & 22231 & 298 \\
\hline \multirow[t]{2}{*}{$\begin{array}{c}\text { Sekolah } \\
\text { Tinggi }\end{array}$} & $\begin{array}{lr}\text { Sekolah Tinggi } & \text { Ilmu } \\
\text { Ekonomi } & \text { Pelita } \\
\text { Indonesia } & \\
\end{array}$ & 1196 & 16 \\
\hline & $\begin{array}{lr}\text { Sekolah } & \text { Tinggi } \\
\text { Manajemen } & \\
\text { Informatika } & \text { dan } \\
\text { Komputer } & \text { (STMIK) } \\
\text { Hangtuah } & \\
\end{array}$ & 308 & 4 \\
\hline \multirow[t]{2}{*}{ Akademi } & $\begin{array}{l}\text { AMIK Tri Dharma } \\
\text { Pekanbaru }\end{array}$ & 155 & 2 \\
\hline & $\begin{array}{l}\text { Akademi Pariwisata } \\
\text { Engku Putri Hamidah }\end{array}$ & 120 & 24 \\
\hline Politeknik & Politeknik Caltex Riau & 1810 & 2 \\
\hline & Total & 33553 & 450 \\
\hline
\end{tabular}

Sumber : Data Olahan (2018)

Jenis dan Sumber Data

Jenis dan sumber data yang digunakan adalah data Primer yaitu data yang berasal dari objek penelitian, yaitu berupa kuisioner dan wawancara yang diberikan secara langsung kepada responden untuk memperoleh informasi tentang kepuasan nasabah.

\section{Metode Pengumpulan Data}

Dalam pengumpulan data penulis menggunakan cara sebagai berikut:

1. Wawancara. Yakni melakukan tanya jawab secara langsung kepada mahasiswa dan karyawan pada Perguruan Tinggi di Kota Pekanbaru

2. Kuisioner. Yakni dengan membuat daftar pertanyaan yang diberikan langsung kepada mahasiswa dan karyawan pada Perguruan Tinggi di

Kota Pekanbaru

\section{Definisi Operasional Variabel}

Tabel 2 Definisi Operasional Variabel

\begin{tabular}{|c|c|c|}
\hline Variabel & Definisi & Atribut / Indikator \\
\hline $\begin{array}{l}\text { System } \\
\text { Quality }\end{array}$ & $\begin{array}{l}\text { Tingkat seberapa besar } \\
\text { teknologi komputer dirasakan } \\
\text { relatif mudah untuk dipahami } \\
\text { dan digunakan. }\end{array}$ & $\begin{array}{l}\text { Fungsionalitas } \\
\text { Kehandalan } \\
\text { Kegunaan } \\
\text { Aksesibilitas } \\
\end{array}$ \\
\hline $\begin{array}{l}\text { Information } \\
\text { Quality }\end{array}$ & $\begin{array}{l}\text { Ukuran kualitas isi sebuah } \\
\text { aplikasi sistem informasi, } \\
\text { tetapi kualitas data sering } \\
\text { digunakan sebagai sinonim. }\end{array}$ & $\begin{array}{l}\text { Akurasi } \\
\text { Ketepatan waktu } \\
\text { Relevansi } \\
\text { Ketelitian } \\
\text { Keinformatifan } \\
\end{array}$ \\
\hline $\begin{array}{l}\text { Service } \\
\text { Quality }\end{array}$ & $\begin{array}{lr}\text { Upaya pemenuhan kebutuhan } \\
\text { yang dibarengi dengan } \\
\text { keinginan konsumen serta } \\
\text { ketepatan } & \text { cara } \\
\text { penyampaiannya agar dapat } \\
\text { memenuhi harapan dan } \\
\text { kepuasan pelanggan tersebut }\end{array}$ & $\begin{array}{l}\text { Kehandalan } \\
\text { Layanan } \\
\text { Respon } \\
\text { Jaminan } \\
\text { Empati }\end{array}$ \\
\hline $\begin{array}{l}\text { User } \\
\text { Satisfaction }\end{array}$ & $\begin{array}{l}\text { Perasaan senang atau kecewa } \\
\text { seseorang yang berasal dari } \\
\text { perbandingan antara kesannya } \\
\text { terhadap kinerja produk yang } \\
\text { riil/aktual dengan kinerja } \\
\text { produk yang diharapkan. }\end{array}$ & $\begin{array}{l}\text { Kemantapan produk } \\
\text { Kebiasaan penggunaan produk } \\
\text { Memberikan rekomendasi } \\
\text { produk } \\
\text { Kemudahan } \\
\text { produk penggunaan } \\
\text { Sesuai dengan harapan } \\
\end{array}$ \\
\hline User Loyalty & $\begin{array}{l}\text { Loyalitas pelanggan adalah } \\
\text { komitmen yang kuat dari } \\
\text { pelanggan untuk berlangganan } \\
\text { kembali atau melakukan } \\
\text { pembelian ulang produk/jasa } \\
\text { yang disukai secara konsisten } \\
\text { di masa yang akan datang. } \\
\end{array}$ & $\begin{array}{l}\text { Trust. } \\
\text { Emotion commitment } \\
\text { Switching cost } \\
\text { Word of mouth } \\
\text { Cooperation }\end{array}$ \\
\hline & rla, Somers \& Wor & $\begin{array}{l}(2010) \\
(2016) \\
(2014)\end{array}$ \\
\hline
\end{tabular}

\section{Uji Validitas dan Reliabilitas}

Uji Validitas

Uji validitas digunakan untuk mengukur sah atau valid tidaknya suatu kuesioner. Suatu kuesioner dikatakan valid jika pertanyaan pada kuesioner mampu untuk mengungkapkan sesuatu yang akan diukur oleh kuesioner tersebut (Sugiyono, 2009). Validitas item-item pertanyaan kuesioner dapat diukur dengan melakukan korelasi antara skor item pertanyaan dengan total skor variabel atau konstruk. Koefisien korelasi yang dihasilkan kemudian dibandingkan dengan $r$ tabel-bila korelasi antara skor item dengan total skor kurang dari 0,30 
(didapat dari perhitungan antara perhitungan interpolasi dari tabel nilai $r$ Product Moment) maka item pertanyaan dalam instrumen tersebut dinyatakan tidak valid. Item instrumen dianggap valid jika lebih besar dari 0,30 dengan membandingkannya dengan $r$ tabel. Jika $r$ hitung $>\mathrm{r}$ tabel maka valid.

\section{Uji Reliabilitas}

Reabilitas adalah alat untuk mengukur suatu kuesioner yang merupakan indikator dari variabel atau konstruk.Suatu kuesioner dikatakan reliabel atau handal jika jawaban responden terhadap pertanyaan adalah konsisten atau stabil dari waktu ke waktu.Tingkat reliabel suatu variabel atau konstruk penelitian dapat dilihat dari hasil uji statistik Crobach Alpha $(\alpha)$. Menurut kriteria Ghozali (2015), variabel atau konstruk dikatakan reliabel jika nilai Cronbach Alpha > 0,60. Semakin nilai alphanya mendekati satu maka nilai reliabilitas datanya semakin terpercaya.untuk masing-masing variabel.

Uji Analisis Jalur (Path Analysis)

Analisis jalur yang di kenal sebagai (path Analysis) dikembangkan pertama pada tahun 1920-an oleh ahli genetika yaitu Sewall Wright. Ghozali, (2015) mengatakan bahwa model path analysis digunakan untuk menganalisis pola hubungan antara variabel dengan tujuan mengetahui pengaruh langsung maupun tidak langsung seperangkat variabel bebas (eksogen) terhadapa variabel eksogen. Ghozali menyatakan, terdapat beberapa asumsi dasar untuk melakukan penenlitian dengan metode path analysis:

1. Hubungan antar variabel harus bersifat linier.

2. Model penelitian memiliki hubungan kausalitas dengan panah satu arah (one-way casual flow), tidak ada hubungan kausalitas terbalik.

3. Variabel endogen minimal dalam skala interval Instrument penelitian harus valid dan reliable

4. Menggunakan sampel probability sampling yaitu tekhnik pengambilan sampel untuk memberikan peluang yang sama pada setiap anggota populasi untuk dipilih menjadi anggota sampel.

5. Model penelitian yang dilakukan dibangun berdasarkan kerangka teoritis tertentu yang mampu menjelaskan hubungan kausalitas antar variabel yang di teliti.

Setelah asumsi dasar tersebut di atas dapat dipenuhi sebagai dasar penelitian metode path analysis, maka tahap awal dalam penerapan model path analiysis yaitu dengan merumuskan persamaan model structural dan diagram jalur berdasarkan kajian teoritis.

Teknik analisis jalur ini akan digunakan dalam menguji besarnya sumbangan (kontribusi) yang ditujukan oleh koefisien jalur pada setiap diagram jalur dari hubungan kausal antar variabel $\mathrm{X}_{1}, \mathrm{X}_{2}, \mathrm{X}_{3}$ terhadap $\mathrm{Y}_{1}$ serta dampaknya terhadap $\mathrm{Y}_{2}$. analisis korelasi dan regresi menjadi dasar dari perhitungan analisis jalur. Berdasarkan hipotesis yang dikemukakan dalam penelitian ini diketahui persamaan struktural, sebagai berikut:

$Y_{1}=\alpha_{0}+\beta_{1} X_{1}+\beta_{2} X_{2}+\beta_{3} X_{3}+\varepsilon_{1}$

$\mathrm{Y}_{2}=\boldsymbol{\alpha}_{0}+\beta_{1} \mathrm{Y}_{1}+\beta_{2} \mathrm{X}_{2}+\beta_{3} \mathrm{X}_{3}+\boldsymbol{\varepsilon}_{2}$

Dimana :

$\mathrm{Y}_{1} \quad$ : User satisfaction

$\mathrm{Y}_{2} \quad$ : User Loyalty

$\alpha_{0} \quad$ : Intercept

$\beta_{1} \ldots \beta_{3}$ : Coefficient Of Variable

$\mathrm{X}_{1} \quad$ : System Quality 
$\mathrm{X}_{2} \quad$ : Information Quality

$\mathrm{X}_{3} \quad$ : Service Quality

$\varepsilon_{1} \ldots . . \varepsilon_{2}:$ Error Term

\section{Analisis Hipotesis}

Persamaan Struktural

1. Struktur Persamaan I

$\mathbf{Y}_{1}=\boldsymbol{\beta}_{1} \mathbf{X}_{1}+\boldsymbol{\beta}_{2} \mathbf{X}_{2}$

User Satisfaction $=0.103 *$ System Quality + $0.942 *$ Information Quality $+0.009 *$ Service Quality

2. Struktur Persamaan II

$Y_{2}=\beta_{1} X_{1}+\beta_{2} X_{2}+\beta_{3} X_{3+} Y_{1}$

User Loyalty $=0.098 *$ System Quality + $0.201 *$ Information Quality $+0.005 *$ Service Quality + 0.005 User Satisfaction

HASIL DAN PEMBAHASAN Analisa Responden berdasarkan Jenis Kelamin

Tabel 3 Analisis frekuensi jenis kelamin

\begin{tabular}{ccc}
\hline Ket. & Frekuensi & Persentase \\
\hline Laki-Laki & 128 & 28.4 \\
Perempuan & 322 & 71.6 \\
Jumlah & 450 & 100 \\
\hline
\end{tabular}

Sumber : Data Olahan (2018)

Berdasarkan table di atas diperoleh bahwa responden dalam penelitian ini berdasarkan jenis kelamin terdiri dari $71.6 \%$ mahasiswa perempuan sedangkan responden mahasiswa laki-laki sebanyak $28.4 \%$.

Analisa Responden berdasarkan tingkat strata pendidikan

Tabel 4 Analisis frekuensi Strata Pendidikan

\begin{tabular}{ccc}
\hline Ket. & Frekuensi & Persentasi \\
\hline D3 & 26 & 5.8 \\
S1 & 406 & 90.2 \\
S2/S3 & 18 & 4 \\
Jumlah & 450 & 100 \\
\hline
\end{tabular}

Sumber : Data Olahan (2018)

Berdasarkan table di atas dapat dilihat mayoritas responden adalah mahasiswa strata satu dengan persentasi 90.2\% sedangkan sisanya adalah mahasiswa 3 sebanyak $5.8 \%$ dan S2/S3 sebanyak $4 \%$.

\section{Uji Validitas dan Reliabilitas}

Uji Validitas dan reliabilitas dilakukan menggunakan spss versi 20. Dimana keseluruhan pernyataan mempeproleh hasil corrected item total correlation > 0,3 yang artinya data valid sedangkan cronbach alpha >0.6 yang artinya seluruh variabel layal atau reliable ke uji selanjutnya.

\section{Uji Kelayakan Model}

Langkah yang harus dilakukan sebelum menilai kelayakan dari model struktural adalah menilai apakah data yang akan diolah memenuhi asumsi model persamaan struktural. Menilai goodness of-fit menjadi tujuan utama SEM untuk mengetahui sampai seberapa jauh model yang dihipotesiskan "fit" atau cocok dengan sampel data (Ghozali, 2014). Hasil goodness of-fit ditampilkan pada tabel berikut:

Tabel 5 Goodness of Fit Result

\begin{tabular}{|c|c|c|c|}
\hline $\begin{array}{l}\text { Goodness } \\
\text { of Fit Index }\end{array}$ & Cut-off* & Results & Conclusion \\
\hline Chi-Square & & 613.094 & \\
\hline Probability & $\geq 0.05$ & 0.000 & Marginal \\
\hline G F I & $\geq 0.90$ & 0.857 & Marginal \\
\hline A GF I & $\geq 0.90$ & 0.821 & Marginal \\
\hline T L I & $\geq 0.90$ & 0.911 & Fit \\
\hline C F I & $\geq 0.90$ & 0.923 & Fit \\
\hline N F I & $\geq 0.90$ & 0.851 & Marginal \\
\hline I F I & $\geq 0.90$ & 0.924 & Fit \\
\hline RMSEA & $\begin{array}{l}0.05- \\
0.08\end{array}$ & 0.059 & Fit \\
\hline $\begin{array}{r}\text { irce: }(\mathrm{H} \\
\mathrm{B}\end{array}$ & $\begin{array}{l}\text { r et al., } \\
\text { dasark }\end{array}$ & hasil & tabel \\
\hline
\end{tabular}


fit. Hal ini ditunjukan pada nilai TLI (0.911), CFI (0.923), IFI (0.924) dan RSMEA (0.059) yang modelnya sudah mencapai kriteria fit sedangkan Probability (0.000), GFO (0.857), AGFI (0.821) dan NFI (0.851) yang hampir mendekati atau marginal. Artinya melalui pengujian ini model dapat dikatakan cocok dan dapat dilanjutkan ke pengujian selanjutnya.

Uji Hipotesis Analisis Jalur (Path Analisis) Dengan Analyisis of Moment Structure (AMOS)

Tabel 6 Uji Hipotesis Analisis Jalur

\begin{tabular}{|c|c|c|c|c|c|}
\hline & $\begin{array}{c}\text { Exogenous } \\
\text { Variable }\end{array}$ & $\begin{array}{c}\text { Endogenous } \\
\text { Variable }\end{array}$ & $\begin{array}{c}\text { Standardized } \\
\text { Coefficient }\end{array}$ & $\begin{array}{c}\text { Critical } \\
\text { Ratio }\end{array}$ & \\
\hline $\mathbf{H}_{1}$ & $\begin{array}{c}\text { System } \\
\text { Quality } \\
\left(X_{I}\right)\end{array}$ & $\begin{array}{c}\text { User } \\
\text { Satisfaction } \\
\left(Y_{1}\right)\end{array}$ & 0.103 & 0.920 & \\
\hline $\mathbf{H}_{2}$ & $\begin{array}{c}\text { Information } \\
\text { Quality } \\
\left(X_{2}\right)\end{array}$ & $\begin{array}{c}\text { User } \\
\text { Satisfaction } \\
\left(Y_{1}\right)\end{array}$ & 0.942 & 6.244 & \\
\hline $\mathbf{H}_{3}$ & $\begin{array}{c}\text { Service } \\
\text { Quality } \\
\left(X_{3}\right)\end{array}$ & $\begin{array}{c}\text { User } \\
\text { Satisfaction } \\
\left(Y_{1}\right)\end{array}$ & 0.009 & 0.082 & \\
\hline $\mathbf{H}_{4}$ & $\begin{array}{c}\text { System } \\
\text { Quality } \\
\left(X_{l}\right)\end{array}$ & $\begin{array}{l}\text { User Loyalty } \\
\qquad\left(Y_{2}\right)\end{array}$ & 0.098 & 0.827 & \\
\hline $\mathbf{H}_{5}$ & $\begin{array}{c}\text { Information } \\
\text { Quality } \\
\left(X_{2}\right)\end{array}$ & $\begin{array}{l}\text { User Loyalty } \\
\qquad\left(Y_{2}\right)\end{array}$ & 0.139 & 0.513 & \\
\hline $\mathrm{H}_{6}$ & $\begin{array}{l}\text { Service } \\
\text { Quality } \\
\quad\left(X_{3}\right)\end{array}$ & $\begin{array}{l}\text { User Loyalty } \\
\qquad\left(Y_{2}\right)\end{array}$ & 0.201 & 1.746 & \\
\hline $\mathbf{H}_{7}$ & $\begin{array}{c}\text { User } \\
\text { Satisfaction } \\
\left(Y_{1}\right)\end{array}$ & $\begin{array}{c}\text { User Loyalty } \\
\qquad\left(Y_{2}\right)\end{array}$ & 0.005 & 0.021 & \\
\hline
\end{tabular}

Sumber : Data Olahan (2018)

Pengaruh System Quality Terhadap User Satisfaction dan User Loyalty

Berdasarkan hasil penelitian diperoleh hasil bahwa kualitas sistem berpengaruh signifikan terhadap kepuasan pengguna, dalam hal ini mahasiswa. Artinya semakin bagus kualitas sistem informasi akademik di perguruan tinggi maka kepuasan mahasiswa sebagai pengguna juga akan meningkat. Hal ini bertolak belakang dengan pengaruhnya terhadap loyalitas pengguna. Melalui penelitian ini diperoleh hasil yang tidak signifikan untuk hubungan antara kualitas sistem dan loyalitas pengguna. Ini berarti kualitas sistem dalam penelitian ini hanya akan mempengaruhi kepuasan pengguna namun belum tentu dapat meningkatkan loyalitasnya.

Kualitas sistem (X2) terdiri dari adaptability, availability, reliability, respon time dan usability. Adaptabilitykemampuan beradaptasi sebagai kemampuan sistem (misalnya: sistem komputer) untuk menyesuaikan diri secara efisien dan cepat pada situasi berbeda. Oleh karena itu sistem adaptif adalah sistem terbuka yang mampu menyesuaikan perilaku sesuai dengan

0.000 perubahan lingkungan atau dari sistem itu sendiri. Kebutuhan untuk mengenali 0.000 perubahan tanpa faktor-faktor lain yang terlibat. Availability tersedianya sistem 0.005 yang handal dalam pengujian dan pemeliharaan. Meningkatkan 0.075 pemeliharaan dan perawatan umumnya lebih mudah dan lebih akurat. Reliability 0.021 kemampuan sistem atau komponen untuk fungsi di bawah kondisi yang dinyatakan 0.033 untuk jangka waktu tertentu. Response time adalah jumlah waktu total yang 0.028 dibutuhkan untuk menanggapi permintaan untuk layanan tertentu. Layanan yang berupa akses informasi ke sistem akademik. Usability adalah kemudahan pengoperasian dan pembelajaran dari sistem informasi akademik. Belajar untuk secara efektif berinteraksi dan mencapai kinerja maksimal.

Pengaruh Information Quality Terhadap User Satisfaction dan User Loyality

Hasil penelitian menunjukkan bahwa kualitas informasi memiliki pengaruh signifikan terhadap masingmasing kepuasan dan loyalitas pengguna. Hal ini berarti semakin tinggi kualitas 
informasi dari suatu sistem akademik Perguruan Tinggi maka mahasiswa sebagai pengguna akan merasa puas dan loyal. Hasil ini menunjukkan perbedaan dengan hasil penelitian terdahulu oleh Negash et al. (2002) yang menunjukkan bahwa kualitas sistem memiliki pengaruh dominan terhadap kepuasan pengguna.

Pengaruh Service Quality Terhadap User Satisfaction dan User Loyality

Hasil penelitian menunjukkan bahwa kualitas pelayanan memiliki pengaruh yang signifikan terhadap masing-masing kepuasan pengguna dan loyalitas. Peningkatan kualitas pelayanan pada perguruan tinggi sangat diperlukan mengingat Karena mahasiswa cenderung memilih university yang memberikan service quality dan student satisfaction yang tinggi (Tahir et al., 2010).

Mahasiswa yang loyal bukan dikarenakan mendapat service quality yang baik. Tetapi service quality yang baik disertai dengan meningkatnya student satisfaction yang akan membuat mahasiswa menjadi loyal. Peningkatan service quality tanpa mengukur tingkat kepuasan mahasiswa, tidak akan efektif meningkatkan student loyalty. Hasil ini sesuai dengan penelitian yang dilakukan oleh (Kim, 2011). Sejalan dengan penelitian (Dib \& Mokhles, 2013) yang menyatakan service quality yang baik saja tidak akan meningkatkan student loyalty di Syria. Memang pada penelitian yang dilakukan di India (Annamdevula \& Bellamkonda, 2016a, 2016b) didapatkan hasil yang menyatakan peran penting service quality terhadap peningkatan student loyalty baik langsung maupun melewati student satisfaction.

\section{PENUTUP}

\section{Kesimpulan}

1. Melalui peningkatan kualitas sistem informasi akademik maka akan dapat meningkatkan kepuasan mahasiswa namun belum tentu dapat meningkatkan loyalitas mahasiswa secara langsung. Namun, secara tidak langsung melalui kepuasan, kualitas sistem dapat meningkatkan loyalitas pengguna/mahasiswa.

2. Peningkatan dan perbaikan informasi akademik juga melalui penelitian ini secara langsung dan tidak langsung dapat berdampak kepada peningkatan kepuasan dan loyalitas mahasiswa.

3. Kualitas pelayanan yang baik dalam sebuah perguruan tinggi menjadi penilaian yang sangat penting dalam meningkatkan kepuasan dan loyalitas mahasiswa.

\section{Saran}

1. Bagi Perguruan Tinggi yang menjadi objek penelitan, hasil penelitian dapat dijadikan rujukan dalam meningkatkan kinerja sistem informasi akademik dan pelayanan yang diberikan kepada mahasiswa. Perkembangan teknologi menuntut segala aspek dapat dilakukan secara efektif dan efisien. Untuk itu melalui perbaikan sistem informasi maka suatu organisasi perguruan tinggi akan mampu bersaing dengan perguruan tinggi lainnya.

2. Bagi peneliti selanjutnya agar dapat mengembangkan variable-variabel yang menjadi modesari atau mediasi lainnya seperti image universitas, promosi universitas, dan lain-lain.

\section{DAFTAR PUSTAKA}

Annamdevula, S., \& Bellamkonda, R. S. (2016a). Effect of Student Perceived Service Quality on Student Satisfaction, Loyalty and Motivation in Indian University. Journal of Service Management, 11(2), 488-517. 
Annamdevula, S., \& Bellamkonda, R. S. (2016b). The effects of service quality on student loyalty: the mediating role of student satisfaction. Journal of Service Management, 11(2), 446-462.

Dib, H., \& Mokhles, A. (2013). The Impact of Service Quality on Student Satisfaction and Behavioral Consequences in Higher Education Services. International Journal of Economy, Management and Social Sciences, 2(6), 285-290.

Ghozali Imam, (2014). Structural Equation Modeling, Badan Penerbit Universitas Diponegoro, Semarang.

Hamzah, M., \& Purwati, A. (2017). Sistem Manajemen Inventori Komputer Menggunakan Near Field Communication Berbasis Android Studi Kasus di STIE Pelita Indonesia Pekanbaru. Journal of Economic, Bussines and Accounting (COSTING), 1(1), 95-104.

https://doi.org/https://doi.org/10.3 1539/costing.v1i1.46

Hamzah, Purwati, A \& Kadir, E. (2018). Quality Evaluation on Private Higher Education Institutions in Pekanbaru, Indonesia (Integrating Kano Model and Quality Function Deployment), REVISTA ESPACIOS 39(17), 24-34. Retrieved from http://www.revistaespacios.com/a 18v39n17/a18v39n17p24.pdf

Jogiyanto, H,M. (2007). Model Kesuksesan Sistem Teknologi Informasi, Edisi 1. Yogyakarta: Penerbit Andi.
Kim, H. J. (2011). Service Orientation, Service Quality, Customer Satisfaction, and Customer Loyalty: Testing a Structural Model. Journal of Hospitality Marketing \& Management, 20(6), 619-637.

McLeod, Raymond, Jr., \& schell, George $\mathrm{P}$, (2008). Sistem Informasi Manajemen. Edisi 10. Jakarta: Salemba Empat

Scheepers, R. and Rose, J. (2001), "Organizational intranets: cultivating information technology for the people by the people", in Dasgupta, S. (Ed.), Managing Internet and Intranet Technologies in Organizations: Challenges and Opportunities, Idea Group Publishing, Hershey, PA, 1-20.

Tahir, I. M., Bakar, N. M. A., \& Ismail, W. Z. W. (2010). ImportancePerformance Analysis of Service Quality among Business Students: An Exploratory Study. Interdiciplinary Journal of Contempory Research of Business, 2(1), 330-341

Telem, M. (1996), "MIS implementation in schools: a systems sociotechnical framework", Computers and Education, 27 (2), 85-93.

Petrides, L. (2004), "Costs and benefits of the workaround: inventive solution or costly alternative", International Journal of Education Management, 18 (2), 100-1088.

Purwati, A. \& Sitompul, S. (2017) Aplikasi Model Kano dalam Pengukuran Kualitas Perguruan Tinggi Swasta Kota Pekanbaru Berdasarkan Perspektif Mahasiswa. Jurnal Cano Economos, 6(2),93-110. 